\title{
Adolescent Drug Addiction Treatment and Weight Gain
}

\author{
Candace C. Hodgkins, MA, LMHC \\ Kevin S. Cahill, BS \\ Anne E. Seraphine, PhD \\ Kimberly Frost-Pineda, MPH \\ Mark S. Gold, MD
}

SUMMARY. Neurotransmitter release in the nucleus accumbens use has been linked to self-administration and learning following drug use. This endogenous reward system is also activated following food intake or sex. Therefore, rebound hyperphagia following abstinence may be a mechanism to replenish the release of neurotransmitters in this reward system, leading to increased weight gain and a rise in Body Mass Index

Candace C. Hodgkins is Chief of Professional Services, Gateway Community Services, Inc., Jacksonville, Florida. Ms. Hodgkins is a doctoral candidate in the Department of Counselor Education at the University of Florida, Gainesville, FL.

Kevin S. Cahill is a MD/PhD student at the University of Florida, Gainesville, FL.

Anne E. Seraphine is Assistant Professor, Department of Educational Psychology, University of Florida College of Education, Gainesville, FL.

Kimberly Frost-Pineda is Coordinator, Research Programs/Services, Division of Addiction Medicine, University of Florida College of Medicine.

Mark S. Gold is Distinguished Professor, Departments of Psychiatry, Neuroscience, Community Health \& Family Medicine, and Chief of Addiction Medicine, University of Florida College of Medicine, Gainesville, FL.

Address correspondence to: Candace C. Hodgkins, Gateway Community Services, Inc., 555 Stockton Street, Jacksonville, FL 32224.

[Haworth co-indexing entry note]: "Adolescent Drug Addiction Treatment and Weight Gain." Hodgkins, Candace C. et al. Co-published simultaneously in Journal of Addictive Diseases (The Haworth Medical Press, an imprint of The Haworth Press, Inc.) Vol. 23, No. 3, 2004, pp. 55-65; and: Eating Disorders, Overeating, and Pathological Attachment to Food: Independent or Addictive Disorders? (ed: Mark S. Gold) The Haworth Medical Press, an imprint of The Haworth Press, Inc., 2004, pp. 55-65. Single or multiple copies of this article are available for a fee from The Haworth Document Delivery Service [1-800-HAWORTH, 9:00 a.m. - 5:00 p.m. (EST). E-mail address: docdelivery@ haworthpress.com].

http://www.haworthpress.com/web/JAD

(C) 2004 by The Haworth Press, Inc. All rights reserved.

Digital Object Identifer: 10.1300/J069v23n03_05 
during recovery from substance abuse. In this report, we examined the relationship between supervised drug abstinence and increased weight gain among adolescents at a residential substance abuse treatment center. Mean weight change over time was followed by repeated analysis of weight and body mass index. Significant weight gain and body mass index increase was observed during supervised and confirmed abstinence from drug use. Furthermore, significant interactions between tobacco use and primary substance use disorder with weight gain was demonstrated by multivariate analysis of variance. [Article copies available for a fee from The Haworth Document Delivery Service: 1-800-HAWORTH. E-mail address: <docdelivery@haworthpress.com>Website: <http://www.HaworthPress. com> (c) 2004 by The Haworth Press, Inc. All rights reserved.]

KEYWORDS. Adolescents, addiction, weight, BMI, drugs

\section{INTRODUCTION}

\section{Substance Abuse and Adolescents}

The use of tobacco, alcohol, and illicit drugs by adolescents has risen for most of the past two decades, with a plateau and then significant declines since $1999 .{ }^{1}$ However, the percentage of adolescents using alcohol and drugs in the U.S. remains shockingly high. According to the 1996 annual Monitoring the Future (MTF) Study, ${ }^{2}$ about one-third of high school seniors reported being drunk in the past month, while one-fifth of 10th and 12th graders used marijuana in that same time period. MTF data from 2002 shows that seniors who reported using alcohol on a daily basis increased from 2.9 percent in 2000 to 3.5 percent in 2002, and past year marijuana use by seniors was at 36.2 percent in $2002 .^{3}$

In addition to high rates of use, adolescents are using substances of abuse at younger and younger ages, ${ }^{3}$ often initiating use between the ages of 10 to 13 with cigarettes, alcohol and then moving to experimentation with marijuana and club drugs. ${ }^{4}$ The 2002 MFT report cited 8.3\% of 8th graders, $17.8 \%$ of 10th graders, and $21.5 \%$ of 12 th graders as current users of marijuana, which, along with tobacco and alcohol, is often called a "gateway drug" to other illicit drug use. ${ }^{5,6}$ While marijuana is the most widely used illicit drug, many adolescents report the use of poly-substances. In recent years, the club drug "ecstasy" (MDMA) increased dramatically. Johnston et al. ${ }^{1}$ reported that use of ecstasy by 
eighth graders rose from $1.7 \%$ in 1999 to $3.5 \%$ in 2001 , while use among 10th and 12th graders increased to almost $10 \%$, making it a drug that is more frequently used than cocaine by adolescents.

\section{Overweight and Obese Adolescents}

The prevalence of adult and adolescent obesity has increased at alarming rates in the past three decades. In fact, adolescent obesity has been described by the Centers for Disease Control and Prevention (CDC) as an epidemic. ${ }^{7}$ This striking increase has been linked to the dramatic rise in Type II Diabetes among young persons. Today, one out of every five youths in the U.S. is overweight ${ }^{7}$ and one in four is at risk of becoming overweight. ${ }^{8}$ Among adults, half are overweight and almost one-quarter suffers from obesity. This translates to approximately 97 million overweight adults and about 40 million obese adults. ${ }^{9}$ The remarkable increase in obesity among adolescents in the U.S. has resulted in recommendations for more exercise, food restriction, and even bariatric surgery. ${ }^{10}$ Complications of childhood obesity include psychosocial, psychological, neurological, cardiovascular, endocrine, musculoskeletal, renal, gastrointestinal, and pulmonary problems. ${ }^{11}$

Overweight is defined as an increase in weight relative to some standard. Obesity is defined as an excessively high amount of body fat or adipose tissue in relation to lean body mass. Body fat distribution can be estimated by a variety of techniques. The three most common techniques for evaluating body weight are life insurance tables, relative weight (actual weight/desirable weight $\times 100$ ), and Body Mass Index (BMI). The standard definition of overweight adults is having a BMI (calculated by weight in kilograms/height in meters squared) between the 85th and 95th percentile, with severe obesity in adults being any BMI greater than the 95th percentile. Calculating BMI is simple and it correlates well with clinical measures, which is why it is commonly used in epidemiological studies. Although there are some exceptions, a BMI above 25 (overweight) and above 30 (obese), is a useful guide to estimate the degree of excess fat and health risk. ${ }^{12}$

For children and adolescents, the CDC recommend using specific charts of calculated BMI values for selected heights and weight for ages 2 to 20 years. ${ }^{13}$ This is due to the change in body fatness as the child ages and develops. CDC defines "at-risk for becoming overweight" as having a BMI between the 85 th percentile and the 95 th percentile for a person's age and gender. Any BMI over the 95th percentile is considered overweight trending toward obesity. 


\section{Substance Abuse and Eating Disorders}

A recent report from SAMHSA ${ }^{14}$ suggests there is a strong correlation among youth between substance abuse and several behavioral and emotional problems. However, little current research focuses on substance use and weight gain, obesity, or eating disorders. In one recent study by Ross and Ivis, ${ }^{15}$ binge eaters were more likely to use all types of substances and a high correlation was found for cannabis use. Adolescent eating disorders and substance abuse are both major public health issues in the U.S. The cost to society for health care related to these problems is extraordinary. Adolescents who are obese and those that are substance dependent often continue to have these problems as adults. Weight in adolescence is a predictor of adult weight ${ }^{16}$ and later adverse health events, as is substance abuse a predictor of future substance abuse and dependence.

We have previously reported that adolescents in a supervised treatment setting gained significant weight while abstinent from alcohol and illicit drugs. Thus it appears important that further research address the particular variables associated with the phenomena, with particular attention to improved treatment program development.

\section{Tobacco Use and Weight Gain}

It has been demonstrated that smokers have a propensity to gain weight when they quit smoking, although on average there is only a 6-8 pound gain for each individual when they quit. ${ }^{17}$ Weight gain in the adult population has been found to be statistically significant over a 10 year period for those individuals who quit smoking versus those individuals who had never smoked, ${ }^{18}$ therefore suggesting that the increase in overweight individuals in the Untied States may be slightly associated with the increase of smoking cessation during that period of time. Research suggests that adult women have a more difficult time of quitting smoking and are more prone to relapse due to weight concerns. ${ }^{19} \mathrm{It}$ also appears that concern about weight gain is correlated with fewer quit attempts and minimal intentions to quit. ${ }^{20}$

Given the various relationships between appetite, taste, drugs of abuse, brain reward pathways and eating disorders, as well as the widespread occurrence of adolescent obesity, many factors must be considered by treatment providers to enhance and refine current modalities regarding adolescent substance abuse treatment. The purpose of this study was to further clarify the relationship of weight gain to abstinence 
from drug use in adolescents. This was accomplished through the analysis of 75 adolescent patients admitted to a residential substance abuse treatment facility between 1999 and 2002. Data obtained from these patients were used to test the following hypotheses:

1. There is significant weight increase during supervised treatment and abstinence from alcohol, illicit drugs, and tobacco.

2. There is an interaction effect between weight increase and smoking.

3. There is an interaction effect between BMI increase and smoking.

4. There is an interaction effect between weight increase and primary drug of choice.

5. There is an interaction effect between BMI increase and primary drug of choice.

\section{METHODS}

\section{Source of Data and Sample}

This study was conducted at an adolescent residential substance abuse treatment center in a southeastern city in the United States. The facility is a 24-bed substance abuse treatment center for males and females, ages 13 through 17 . This population of adolescents is referred to the treatment program by three different means: self-referral, civil commitment by parents, or adjudicated by the court system. The adolescent participants in this program are supervised on the campus twenty-four hours a day, seven days a week with the average length of stay amounting to 168 days. The center is a non-secure facility. All participants are required to abstain from all alcohol, illicit drug use and tobacco during time of treatment. Drug screens are obtained when participants leave campus for any reason and participants are also randomly tested during their stay at the facility. All information for this study was obtained from existing data sets held in reserve for outcome measures by the organization. Each participant in treatment signs a consent form giving the organization permission to use data from the charts for research purposes, by qualified individuals, with the understanding that all identifying information will be kept confidential. This research project was reviewed and approved by the University of Florida Institutional Review Board. 
A total of 215 male $(n=148)$ and female $(n=67)$ patients were involved in treatment for varying lengths of time from the beginning of August 1999 until the end of July 2002. The mean age for the sample was 15.8 years. The majority of the patients were male $(\mathrm{n}=109$; $70.3 \%)$, whereas almost thirty percent were female $(n=46 ; 29.7 \%)$. The group consisted of $80.1 \%$ non-Hispanic white and $17.9 \%$ African American patients, with the remaining $1.9 \%$ of patients from other ethnicities. There was a higher percentage of smokers, $82.4 \%$, than nonsmokers, $17.6 \%$. Patients diagnosed according to DSM-IV criteria for cannabis abuse equaled $19.2 \%$, cannabis dependence equaled $57.7 \%$, and polysubstance abuse equaled $23.2 \%$. After excluding patients in treatment for fewer than thirty days and patients with incomplete data sets, 75 patients were randomly chosen for inclusion in this analysis.

\section{Analysis}

For this two between subjects factor (i.e., smoking and SUD) and one within subjects factor (time in treatment: admit date, 60 days, 90 days, and discharge) design, the most suitable statistical procedure was a multivariate analysis of variance. Although there were a total of eight different primary SUD diagnoses reported in this patient population, only those diagnoses that equaled more than 10 in a cell were analyzed. The SUD's meeting that criterion were Cannabis Abuse, Cannabis Dependence, and Poly-Substance Dependence. For this study, SPSS was used for the statistical analysis. All statistical tests were conducted at $\alpha=.05$.

\section{RESULTS}

Two separate MANOVAs were conducted, one for each of the two outcome measures: weight and BMI. The results of the MANOVAs are reported in Tables 1 and 2 for weight and BMI, respectively. For each outcome variable, time in treatment and the interaction between smoking and time in treatment were statistically significant. These two effects were also practically significant, given that the eta squared values showed both effects to be large according to Cohen' ${ }^{21}$ criterion.

The descriptive statistics for weight and BMI are reported in Table 3. There was a substantial weight gain and BMI increase from admittance to 60 days. Participants gained an average of about 11 pounds and in- 
TABLE 1. MANOVA for Weight

\begin{tabular}{lccccc}
\hline Effect & Pillai's Trace & \multicolumn{1}{c}{$\mathrm{F}$} & $\mathrm{df}$ & $\mathrm{p}$ & Eta Squared \\
\hline Time & .515 & 23.69 & 3,67 & .00 & .515 \\
Time ${ }^{\star}$ Smoke & .127 & 3.26 & 3,67 & .03 & .127 \\
Time $^{\star}$ Drug & .131 & 1.58 & 6,136 & .16 & .065 \\
Time $^{*}$ Smoke & .065 & .76 & 6,136 & .61 & .032 \\
\hline
\end{tabular}

TABLE 2. MANOVA for BMI

\begin{tabular}{lccccc}
\hline Effect & Pillai's Trace & $\mathrm{F}$ & $\mathrm{df}$ & $\mathrm{p}$ & Eta Squared \\
\hline Time & .469 & 19.72 & 3,67 & .00 & .469 \\
Time ${ }^{*}$ Smoke & .123 & 3.15 & 3,67 & .03 & .123 \\
Time*Drug & .153 & 1.87 & 6,136 & .09 & .076 \\
Time*Smoke*Drug & .044 & .51 & 6,136 & .80 & .022 \\
\hline
\end{tabular}

creased their BMI by 1.58 during this time. Mean weight gain was less from 60 days to discharge. In addition to weight and BMI, Table 3 indicates the percentage of the patients who are at-risk for being overweight and those who are overweight. The CDC defines at-risk for becoming overweight as having a BMI between the 85th percentile and the 95th percentile for a person's age and gender. Consequently, by definition, $10 \%$ of the population would be expected to be at-risk for becoming overweight. The percent of patients at-risk for becoming overweight increased after admittance to the program, going from $7.1 \%$ at admittance and increasing to $14.7 \%$, a percentage that is above the expected $10 \%$ for a gender and age matched population. Similarly, CDC defines being overweight as having a BMI above the 95th percentile for a person's age and gender. Again, this definition leads to an expectation that $5 \%$ of the population is overweight. Upon admittance, the sample was slightly higher $(5.8 \%)$ than expected for the population (5\%). At 60 days, the percent overweight was almost double the population expectation. By the time of discharge, the percent overweight was 2.7 times the expected $(13.5 / 5=2.7)$. Table 3 shows a clear trend toward weight gain for participants in the program, especially during the first 60 days of treatment.

Descriptive statistics for effect of smoking on weight gain are reported in Table 4. The means for weight and BMI gain show substantial gains only from admission to 60 days. The interaction is due to the 
TABLE 3. Descriptive Statistics for Weight and BMI Over Time

\begin{tabular}{|c|c|c|c|c|}
\hline & Admit & 60-Day & 90-Day & Discharge \\
\hline $\begin{array}{c}\text { Weight }- \text { Mean } \\
-(\text { SD) }\end{array}$ & $\begin{array}{l}147.91 \\
(31.27)\end{array}$ & $\begin{array}{l}160.27 \\
(32.22)\end{array}$ & $\begin{array}{l}165.57 \\
(31.18)\end{array}$ & $\begin{array}{l}160.19 \\
(30.90)\end{array}$ \\
\hline $\begin{array}{c}\text { BMI - Mean } \\
-(\mathrm{SD})\end{array}$ & $\begin{array}{l}23.26 \\
(4.84)\end{array}$ & $\begin{array}{c}24.90 \\
(4.65)\end{array}$ & $\begin{array}{c}25.03 \\
(4.23)\end{array}$ & $\begin{array}{l}25.00 \\
(4.63)\end{array}$ \\
\hline$\%$ At-Risk for Overweight* & 7.1 & 12.2 & 14.7 & 13.5 \\
\hline$\%$ Overweight* & 5.8 & 9.6 & 10.3 & 13.5 \\
\hline
\end{tabular}

TABLE 4. Means for Weight and BMI by Smoking

\begin{tabular}{lcccc}
\hline & Admit & 60 -Day & 90-Day & Discharge \\
\hline Weight & & & & \\
$\quad$ Smoking & 147.63 & 161.99 & 167.83 & 160.16 \\
$\quad$ Non-Smoking & 145.06 & 153.74 & 152.56 & 156.91 \\
BMI & & & & \\
$\quad$ Smoking & 23.37 & 25.16 & 25.26 & 25.18 \\
$\quad$ Non-Smoking & 22.23 & 23.90 & 23.58 & 23.80 \\
\hline
\end{tabular}

larger weight and BMI gain for adolescents who smoked prior to treatment.

\section{DISCUSSION}

This study demonstrates that there is significant weight and BMI increase while adolescents are residing in a supervised substance abuse treatment setting. It is evident that both weight gain and BMI over time are influenced by weather or not the individual smokes prior to treatment. The rate of weight and BMI gain from 0-60 days was the highest for smokers. No interaction effect for primary diagnosis was shown. These data suggest that adolescents who smoke are at greater risk of weight gain during supervised abstinence from drugs, including tobacco, and alcohol, increasing their propensity to become at risk of being overweight. 
Regardless of the initial external decisions that prompted drug use, once in the body the drug promotes continued drug seeking behavior. The impact of drugs, tobacco, and alcohol on the brain is modulated by reinforcement and neuroadaptation that contribute to the process of addiction. The ventral tegmental area and the basal forebrain contain the general reward circuitry and the use of drugs can change the neural processes around these connections. These two areas are connected by the mesolimbic dopamine system that is critical to the self-administration of psychomotor stimulants ${ }^{22}$ with motivational behavior acting as a crucial function. ${ }^{23}$ Food, tobacco, and illicit drugs are all reported to be addictive or stimulating to the brain reward system. ${ }^{24}$ Food ingestion, as well as smoking and other drug self-administration, is linked to the neurotransmitter dopamine and is the subject of current studies. ${ }^{25-27}$

It has been suggested that individuals who are prone to drug or food addiction may have a deficiency of dopamine. Wang et al. ${ }^{27}$ tested the hypothesis that obese individuals have abnormalities in brain dopamine activity. They determined that striatal dopamine receptor (DRD2) availability was significantly lower in obese individuals than in the control group. The BMI correlated negatively with the measures of D2 receptors, suggesting that individuals with the largest BMI had the lowest D2 values. Thanos et al. ${ }^{28}$ studied ethanol preferring rats over-expressing the DRD2. Their results suggest that an increase in DRD2 results in reductions in alcohol preference and alcohol intake. These two molecular studies underscore the concept that the under-expression of dopamine receptors in the brain may lead to both food and drug addiction. These findings support the necessity of further examining the issue of weight gain during supervised drug abstinence and the influence of other factors such as tobacco status.

Adolescence is a time of numerous developmental changes from various influences. Adolescence is also a time of self-consciousness about body image and perceived looks, influenced by the power of being accepted or rejected by peers. ${ }^{29}$ In this study, $36.1 \%$ of adolescents entered treatment either underweight or at normal weight, while only $21.9 \%$ remained in this category at discharge. It is possible to speculate that tobacco and illicit drugs may be partially sought as a weight control measure. Therefore, an inordinate amount of weight gain during treatment may lead to depression and may be viewed as a significant relapse issue that must be addressed. There are also numerous physical complications of excessive weight gain, such as heart disease, breathing, and joint problems, and the dramatic increase in Type II diabetes (previ- 
ously called "adult onset diabetes"), which until recently was almost non-existent in children and adolescents. ${ }^{11}$

This study has widespread implications for the field of addiction medicine when determining treatment protocols and assessing adolescents during treatment. Treatment providers pay close attention to dealing with alcohol, tobacco, and illicit drug use in the treatment settings, but the effects of abstinence on weight gain are not addressed. Most programs do not spend significant time on nutritional counseling, exercise, and education concerning the substitution of food for drugs of choice. Further research is needed to examine effective treatment protocols in these areas. Larger data sets with both smokers and non-smokers, females, ethnic populations, and the effects of co-occurring disorders treated with medication may be explored to address the relationship of appetite, drug withdrawal, and coping in an adolescent population.

\section{REFERENCES}

1. Johnston LD, O’Malley PM, Bachman JG. The Monitoring the future national results on adolescent drug use, 1975-2000. 2001. Bethesda, Maryland: U.S. Department of Health and Human Services, National Institutes of Health; 2000.

2. Johnston LD, O'Malley PM, Bachman JG. The Monitoring the future national results on adolescent drug use: Overview of key findings. 1995. Bethesda, Maryland: U.S. Department of Health and Human Services, National Institutes of Health; 1996.

3. American Academy of Pediatrics, Committee on Substance Abuse. Alcohol use and abuse: A pediatric concern. Pediatrics 2001;108:185-189.

4. Johnson PB, Boles SM, Kleber HD. The relationship between adolescent smoking and drinking and likelihood estimates of illicit drug use. J Addictiv Dis. 2000; 19:75-81.

5.. Lai S, Lai H, Page JB, et al. The association between cigarette smoking and drug abuse in the United States. J Addictiv Dis. 2000; 19:11-24.

6. Weinberg NZ, Rahdert E, Colliver JD. Adolescent substance abuse: A review of the past 10 years. J Am Acad Child Adolesc Psychiatry. 1998;37:252-261.

7. Dietz W. Childhood obesity. In: Shils M, Olsen J, Shike M, et al., editors. Modern Nutrition in Health and Disease. Ninth edition. Baltimore: Williams and Wilkins; 1999. pp. 1071-1080. 2000.

8. CDC. Youth risk behavioral surveillance. Atlanta: Centers for Disease Control;

9. Cunningham E, Marcason W. Obesity update. J Am Diet Assoc. 2001;101:80.

10. Yanovski JA. Intensive therapies for pediatric obesity. Ped Clin Nor Amer. 2001;48:1041-1053.

11. Ebbeling CB, Pawlak DB, Ludwig DS. Childhood obesity: Public-health crisis, common sense cure. Lancet. 2002; 360:473-482. 
12. Bray GA, Bouchard C, James WP, editors. Handbook of Obesity. New York: Marcel Dekker; 1997.

13. CDC. (2000). Body mass index-for-age: BMI is used differently with children than it is with adults. Retrieved 9-2, 2002, from http://www.cdc.gov/nccdphp/dnpa/ bmi/bmi-for-age.htm

14. SAMHSA. SAMHSA study links behavior problems, alcohol use. Brown Univ Dig Addict Theory Appl. 2000;19: 5-6.

15. Ross HE, Ivis F. Binge eating and substance use among male and female adolescents. Inter J Eat Dis. 1999;26:245-260.

16. Whitaker RC, Wright JA, Pepe MS. Predicting obesity in young adulthood from childhood and parental weight. NEJW. 1997;337:869-873.

17. Fact Sheet No.11. (2001). What happens when you stop smoking. Available: http://www.ash.org.uk/html/factsheets/html/fact11/html; accessed 1/16/03.

18. Flegal KM, Troiano RP, Pamuk ER, et al. The influence of smoking cessation on the prevalence of overweight in the United States. NEJM. 1995; 333: 1165-1170.

19. Pomerleau CS, Pomerleau OF, Namenek RJ, Mehringer BA. Short-term weight gain in abstaining women smokers. J Subst Abuse Treat. 2000; 18:339-342.

20. Weekley CK, Klesges RC, Relyea G. Smoking as a weight control strategy and its relationship to smoking status. Addict Behav. 1992; 17:259-271.

21. Cohen J. Statistical Power Analysis for the Behavioral Sciences (2nd ed.). Mahwak, New Jersey: Laurence Erlbaum Associates, 1988.

22. Roberts AJ, Koob GF. The neurobiology of addiction: An overview. Alcohol Health \& Res World 1997;21: 101-106.

23. Tenth Special Report to the United States Congress on Alcohol and Health. Alcohol, the brain, and behavior: Mechanisms of addiction. Alcohol Research \& Health 2000;24:12-15.

24. Gold MS, Johnson C, Stennie K. Eating disorders. In Substance Abuse: A Comprehensive Textbook. Ninth edition, Lowenstein JH, Ruiz P, Millman RB, Langrod JD (eds.). Baltimore: Williams and Wilkins. 1997. pp. 319-330.

25. Linseman MA, Harding S. Alcohol consumption following bidirectional shifts in body weight in rats. Psychopharmacology 1989; 97:103-107.

26. NIDA. 2001. Dopamine receptors implicated in obesity. Available http:// www.nida.nih.gov; Accessed 7-19-01.

27. Wang GJ, Volkow ND, Logan J, et al. Brain dopamine and obesity. Lancet. 2001; 357:354-357.

28. Thanos PK, Volkow ND, Freimuth P, et al. Overexpression of dopamine D2 receptors reduces alcohol self-administration. J Neurochem. 2001; 78:1094-1103.

29. Nowinski J. Substance Abuse in Adolescents and Young Adults. New York: W.W. Norton and Company, 1990. 